\title{
Cronobacter sakazakii ATCC 29544 Autoaggregation Requires FliC Flagellation, Not Motility
}

\author{
Jennifer L. Hoeflinger and Michael J. Miller* \\ Department of Food Science and Human Nutrition, University of Illinois at Urbana Champaign, Urbana, IL, USA
}

Cronobacter sakazakii is an opportunistic nosocomial and foodborne pathogen that causes severe infections with high morbidity and mortality rates in neonates, the elderly, and immunocompromised individuals. Little is known about the pathogenesis mechanism of this pathogen and if there are any consequences of $C$. sakazakii colonization in healthy individuals. In this study, we characterized the mechanisms of autoaggregation in C. sakazakii ATCC 29544 (CS29544). Autoaggregation in CS29544 occurred rapidly, within $30 \mathrm{~min}$, and proceeded to a maximum of $70 \%$. Frameshift mutations in two flagellum proteins (FIhA and FliG) were identified in two nonautoaggregating CS29544 clonal variant isolates. Strategic gene knockouts were

OPEN ACCESS

Edited by:

Juan Aguirre,

Universidad de Chile, Chile

Reviewed by:

Ondřej Holý,

Palacký University, Olomouc, Czechia Julio Parra-Flores,

University of the Bío Bío, Chile

Séamus Fanning,

University College Dublin, Ireland

${ }^{*}$ Correspondence:

Michael J. Miller

mille216@illinois.edu

Specialty section:

This article was submitted to

Food Microbiology,

a section of the journal

Frontiers in Microbiology

Received: 06 December 2016

Accepted: 14 February 2017

Published: 28 February 2017

Citation:

Hoeflinger JL and Miller MJ (2017)

Cronobacter sakazakii ATCC 29544

Autoaggregation Requires FliC

Flagellation, Not Motility.

Front. Microbiol. 8:301.

doi: 10.3389/fmicb.2017.00301 generated to determine if structurally intact and functional flagella were required for autoaggregation in CS29544. All structural knockouts ( $\Delta$ flhA, $\Delta$ fliG, and $\Delta f l i C$ ) abolished autoaggregation, whereas the functional knockout $(\triangle m o t A B)$ did not prevent autoaggregation. Complementation with $\mathrm{FliC}(\Delta \mathrm{fliC} / \mathrm{cfliC})$ restored autoaggregation. Autoaggregation was also disrupted by the addition of exogenous wild-type CS29544 filaments in a dose-dependent manner. Finally, filament supercoils tethering neighboring wild-type CS29544 cells together were observed by transmission electron microscopy. In silico analyses suggest that direct interactions of neighboring CS29544 FliC filaments proceed by hydrophobic bonding between the externally exposed hypervariable regions of the CS29544 FliC flagellin protein. Further research is needed to confirm if flagella-mediated autoaggregation plays a prominent role in C. sakazakii pathogenesis.

Keywords: autoaggregation, Cronobacter sakazakii, flagella, FliC, protein-protein interactions

\section{INTRODUCTION}

Cronobacter spp. are motile, biofilm-forming, facultative anaerobic Gram-negative bacilli. Cronobacter sakazakii, formerly known as Enterobacter sakazakii (Iversen et al., 2008), the most prominent species, is an opportunistic pathogen associated with fatal infections in neonates and immunocompromised children and adults (Lai, 2001). Most notably, C. sakazakii infections in neonates have been linked epidemiologically to the consumption of powdered infant formula (PIF) (Biering et al., 1989; Simmons et al., 1989; van Acker et al., 2001). Furthermore, C. sakazakii withstands desiccation in PIF and thrives in reconstituted PIF, especially when PIF is temperatureabused (Breeuwer et al., 2003; Riedel and Lehner, 2007; Osaili et al., 2009). In response, medical and health professionals had been cautioned regarding the use of PIF; however, C. sakazakii infections in neonatal units are not solely due to consumption of contaminated PIF (Jason, 2012). 
For example, C. sakazakii has been reported in infants exclusively breastfed (Hurrell et al., 2009b; Broge and Lee, 2013; Ravisankar et al., 2014). Another concern is the frequency with which nasogastric tubes are used to deliver enteral nutrition in premature neonates (Axelrod et al., 2006). A surveillance study reported that several species of Enterobacteriaceae, including a single C. sakazakii isolate, were recovered from used nasogastric enteral feeding tubes (Hurrell et al., 2009b). These researchers cautioned that microbial biofilms on nasogastric enteral feeding tubes might serve as a continuous inoculum during bolus feedings while the tube is in place. A simple solution may be to switch from indwelling nasogastric tubes to insertion of a nasogastric tube at each feeding; however, the comfort of the neonate and associated economic costs must be considered (Symington et al., 1995). A multifactorial approach to protecting neonates from microbial infections associated with feedings is needed, including identification of the mechanisms C. sakazakii uses during biofilm formation and gastrointestinal colonization.

Many bacteria, especially pathogens, have developed elaborate mechanisms to permit attachment to and formation of dense sessile mono- or polymicrobial aggregates on biotic and abiotic surfaces (Costerton et al., 1987; An and Friedman, 1998; Schluter et al., 2015). Following this initial attachment, bacterial aggregates can cooperatively form biofilms, thereby increasing their chance of survival. Herein, the formation of monospecies aggregates is referred to as autoaggregation. Autoaggregation is common in the Enterobacteriaceae family, including Escherichia coli (Girón et al., 1991; Czeczulin et al., 1997; Prigent-Combaret et al., 2000; Schembri et al., 2001; Sherlock et al., 2005; Girard et al., 2010; Nakao et al., 2012), Salmonella spp. (Collinson et al., 1993), Klebsiella pneumoniae (Favre-Bonte et al., 1995), Edwardsiella tarda (Gao et al., 2015), Citrobacter freundii (Bai et al., 2012), Yersina pestis (Vadyvaloo et al., 2015), and Proteus mirabilis (Rocha et al., 2007; Alamuri et al., 2010), and often occurs via self-recognizing cell-surface appendages. Autoaggregation is mediated by adhesins (Sherlock et al., 2005; Alamuri et al., 2010; Girard et al., 2010; AbdelNour et al., 2014; Arenas et al., 2015; Wang et al., 2015) and other cell-surface molecules, such as surface-associated proteins (Prigent-Combaret et al., 2000; Gao et al., 2015), pili (Girón et al., 1991), fimbriae (Nataro et al., 1992; Collinson et al., 1993; Czeczulin et al., 1997; Schembri et al., 2001), flagella (Sjoblad et al., 1985; Näther et al., 2006), and lipopolysaccharides (Nakao et al., 2012; Wang et al., 2012). Using microscopy, supercoiling between neighboring microorganisms promoted by pili in Escherichia coli was observed (Girón et al., 1991). Additionally, autoaggregation was mediated by flagella in Pseudomonas marina (Sjoblad et al., 1985) and Pyrococcus furiosus (Näther et al., 2006). The gastrointestinal colonization of two Escherichia coli pathotypes occurs via different fully characterized mechanisms of autoaggregation. Bundle-forming fimbriae (AAF/I and AAF/II) in enteroaggregative $E$. coli promote autoaggregation and biofilm formation along the intestinal surface (Nataro et al., 1992; Czeczulin et al., 1997), whereas enteropathogenic E. coli adheres to the intestinal surface via interactions between Intimin and Tir (Donnenberg and Kaper, 1991) and establishes threedimensional microcolonies using bundle-forming pili (Girón et al., 1991). Although autoaggregation was observed in some C. sakazakii strains (Lehner et al., 2005; Wang et al., 2012; Hu et al., 2015), the extracellular factor mediating autoaggregation in C. sakazakii and its biological function were not described.

The role of bacterial flagella in motility and bacterial chemotaxis is well characterized (Sourjik and Wingreen, 2012), but motility is not its sole biological function. Bacterial flagella contribute to the virulence of bacterial pathogens, including adhesion, microcolony formation, invasion, and biofilm formation, as reviewed by others (Haiko and WesterlundWikström, 2013). Unlike other Enterobacteriaceae, the contribution of C. sakazakii's flagellum to its virulence has received little attention. The flagella of C. sakazakii ES5 are required for adhesion to Caco-2 monolayers and biofilm formation to microtiter plates (Hartmann et al., 2010). Herein, we describe the role played by the bacterial flagella in the autoaggregation of C. sakazakii ATCC 29544 (CS29544). A collection of gene knockout and complementation strains revealed that structurally intact FliC containing filaments were required for autoaggregation. Additionally, we provide evidence to suggest that direct interactions between neighboring filaments promote autoaggregation of liquid CS29544 cultures.

\section{MATERIALS AND METHODS}

\section{Bacterial Strains and Growth Conditions}

CS29544 was cultured in brain heart infusion (BHI) broth (Becton Dickinson), pH 7.38 at $37^{\circ} \mathrm{C}$ overnight aerobically with agitation (250 rpm) unless specified. CS29544 was enumerated and spread-plated on BHI agar plates following serial dilution in $1 \times$ phosphate buffered saline (PBS; Dulbecco's Formula), $\mathrm{pH}$ 7.4. Escherichia coli was cultured in lysogeny broth (LB, Miller's formula) at $37^{\circ} \mathrm{C}$ overnight aerobically with agitation $(250 \mathrm{rpm})$ unless specified. When necessary, ampicillin or chloramphenicol were added to BHI or LB at a final concentration of 100 and $35 \mu \mathrm{g} / \mathrm{mL}$, respectively. To test for motility, CS29544 were grown on $0.4 \%$ agar composed of $3 \mathrm{~g} / \mathrm{L}$ beef extract, $10 \mathrm{~g} / \mathrm{L}$ Bacto peptone, $5 \mathrm{~g} / \mathrm{L}$ sodium chloride (BPN) supplemented with $1 \%$ of 2, 3, 5-triphenyltetrazolium chloride (redox indicator) or observed microscopically by wet mount.

\section{Autoaggregation Assays}

Stationary phase CS29544 cultures, grown in $10 \mathrm{~mL} \mathrm{BHI}$ at $37^{\circ} \mathrm{C}$, were held statically at room temperature $\left(\sim 25^{\circ} \mathrm{C}\right)$ for $6 \mathrm{~h}$ to allow autoaggregation. The change in optical density at $600 \mathrm{~nm}$ was gently measured at $30 \mathrm{~min}$ intervals for $2 \mathrm{~h}$ followed by $1 \mathrm{~h}$ intervals until $6 \mathrm{~h}$. Autoaggregation was reported as the maximum percent autoaggregation. Typically the endpoint was used, and calculated by Equation (1).

$$
\text { Percent of autoaggregation }=\frac{1-O D_{\text {time point }}}{O D_{\text {initial }}} * 100
$$

Several additional autoaggregation assays were conducted with modifications after the growth of CS29544 in $10 \mathrm{~mL}$ BHI, including static incubation at different temperatures (4 and $37^{\circ} \mathrm{C}$ ), the addition of $50 \mathrm{mM}$ EDTA or PBS, and before and 
after blending at "whip" speed for $30 \mathrm{~s}$ (BL113SG; Black and Decker). Furthermore, autoaggregation assays were completed with CS29544 following growth in $10 \mathrm{~mL} \mathrm{BHI}$ at different $\mathrm{pH}$ values $(\mathrm{pH}=4,5,6,7.38$, and 8 ) or incubated anaerobically $\left(90 \% \mathrm{~N}_{2}, 5 \% \mathrm{CO}_{2}, 5 \% \mathrm{H}_{2}\right)$. Finally, autoaggregation assays were run with CS29544 following growth $(10 \mathrm{~mL})$ in different media, including Miller and Lennox LB formulations (LB10 and LB5, respectively), tryptic soy broth (TSB), and BPN broth.

Stationary phase CS29544 and nonautoaggregating clonal variant $(\mathrm{CV})$ cultures (described below) grown in BHI were mounted and held statically at room temperature for $1 \mathrm{~h}$ to allow autoaggregation. Still images were taken every $10 \mathrm{~s}$ for a total of $1 \mathrm{~h}$ by a stationary DSLR camera (Rebel T2i; Canon) with an intervalometer. Images (360 frames) were stitched together to create a video file with 24 frames per second. An additional time lapse video was constructed as previously described with the CS29544 and flagellum competition assays (described below) with still images taken every $20 \mathrm{~s}$ for a total of $6 \mathrm{~h}$. Images $(1,080$ frames) were stitched together to create a video file with 72 frames per second.

\section{Isolation of Nonautoaggregating CS29544 Clonal Variants}

Stationary phase CS29544 cultures autoaggregated for $2 \mathrm{~h}$. Then, two separate $100 \mu \mathrm{L}(1 \% ; \mathrm{v} / \mathrm{v})$ aliquots, one from the top fraction of the CS29544 culture and one from the bottom fraction (autoaggregating control) were passed into two fresh tubes of $10 \mathrm{~mL}$ BHI broth and incubated as described above. Successive passages following autoaggregation continued until autoaggregation was arrested. Two independent nonautoaggregating variants were isolated and characterized.

\section{DNA Extraction and Whole-Genome Sequencing}

Genomic DNA was isolated from CS29544 and CVs using the UltraClean ${ }^{\circledR}$ Microbial DNA Isolation Kit (MoBio Laboratories) according to manufacturer's instructions. High-quality genomic DNA libraries were prepared and sequenced using the Illumina platform by the DNA Services group affiliated with the Roy J. Carver Biotechnology Center at the University of IllinoisUrbana Champaign. Paired-end libraries of CS29544 and CVs were prepared with the TruSeq Genomic DNA Sample Prep Kit (length: 200-600 bp) and sequenced on a HiSeq2500 with the TruSeq SBS Sequencing Kit v1 producing a mean read length of 160 nt. An additional mate-pair library of CS29544 was prepared with the Nextera Mate Pair Library Sample Prep Kit (length: 3-8 kbp) and sequenced on a MiSeq V3 with the MiSeq 600 -cycle Sequencing Kit v3 producing a mean read length of 300 nt. Paired-end reads were imported into CLC Genomics Workbench v7.5, and quality and adapter trimmed using default settings. Mate-pair reads were quality and adapter trimmed using Cutadapt (Martin, 2011) and an in-house Perl script provided by the Roy J. Carver Biotechnology Center. Processed matepair reads were imported into CLC Genomics Workbench and de novo assembled using default parameters, and only contigs larger than 1,000 bp were kept. The paired-end reads were mapped to the CS29544 de novo assembly and putative single nucleotide polymorphisms were identified (>90\% frequency) using the Basic Variant Detection tool with default parameters confirmed by targeted Sanger sequencing using an ABI 3730XL capillary sequencer (Life Technologies).

\section{Construction of CS29544 Gene Knockout Strains and Complementation Vector}

Targeted gene disruptions (flhA, fliG, $\operatorname{mot} A B, f l i C$, and flaA) were constructed in the wild-type CS29544 using the lambda Red recombinase system (Cherepanov and Wackernagel, 1995; Datsenko and Wanner, 2000). All bacterial strains, plasmids, and primers used in this study are listed in Tables 1, 2. Briefly, linear DNA fragments were amplified by PCR with pKD3 DNA using the target gene specific primer set (60 bp) and appropriate experimental conditions. CS29544 containing the pKD46 plasmid were grown in $10 \mathrm{~mL}$ of $\mathrm{LB}$ containing $10 \mu \mathrm{g} / \mathrm{mL}$ of ampicillin and $10 \mathrm{mM} \mathrm{L}$-arabinose at $30^{\circ} \mathrm{C}$ overnight aerobically with agitation (250 rpm). CS29544 pKD46 electrocompetent cells were transformed with $500 \mathrm{ng}$ of the purified linear DNA fragment. The FRT-Cm ${ }^{\mathrm{r}}$-FRT cassette in the recombinant mutants was cured by transformation and subsequent removal of the temperature-sensitive flippase (FLP) recombinase helper plasmid (pCP20). The double gene knockout ( $f$ liC and $f l a A$ ) was constructed as described above for the CS29544 $\triangle$ flaA strain. Gene disruptions were confirmed by junction fragment PCR using the appropriate primer sets and experimental conditions.

A fliC complementation vector was constructed by GenScript. Briefly, a 1,011 bp sequence, containing the fliC coding sequence and native promoter, was obtained from the publically available CS29544 genome (NCBI Reference Sequence: NZ_CP011047.1). The entire DNA fragment was synthesized and cloned into the pET-11a vector with the restriction enzymes BglII and BamHI. The cfliC vector was electroporated into E. coli Top10 and subsequently electroporated into the CS29544 $\Delta$ fliC and $\triangle f l a A \Delta f l i C$ strains using LB broth. Putative complements were grown in BHI or on motility agar plates supplemented with $50 \mu \mathrm{g} / \mathrm{mL}$ ampicillin. Restoration of wild-type function was assessed by autoaggregation assays, motility assays, microscopy, and flagella harvest as detailed above and below.

\section{Flagella Staining and Microscopy}

The presence of extracellular flagella of CS29544, gene knockout, and complementation strains were determined by a combination of imaging techniques. Log or stationary phase CS29544, gene knockout, and complementation cultures were stained using a crystal violet-based flagella stain (Hardy Diagnostics) according to manufacturer's instructions. Stains were visualized using a light microscope at $1,000 \times$ total magnification (BA210; Motic). Images were captured with a 2-megapixel Motic camera.

Several overnight colonies of CS29544, gene knockout, and complementation strains were gently lifted from BHI agar plates and suspended in phosphate buffered Karnovsky's fixative containing 2\% glutaraldehyde and $2.5 \%$ paraformaldehyde. Transmission electron microscopy (TEM) was completed by the 
TABLE 1 | Bacterial strains and plasmids used in this study.

\begin{tabular}{|c|c|c|c|}
\hline Strain or plasmid & Relevant characteristics or purpose & Internal number & Source or references \\
\hline \multicolumn{4}{|c|}{ C. SAKAZAKII STRAINS } \\
\hline CS29544 & Cronobacter sakazakii ATCC 29544, wild-type & MJM187 & ATCC \\
\hline flhA_CV (2.10) & CS29544 flhA nonautoaggregating variant & MJM387 & This study \\
\hline fliG_CV (3.6) & CS29544 fliG nonautoaggregating variant & MJM388 & This study \\
\hline$\Delta \mathrm{f} / \mathrm{h} A$ & CS29544 flhA & MJM425 & This study \\
\hline$\triangle \operatorname{mot} A B$ & CS29544 motAB & MJM476 & This study \\
\hline$\Delta$ flic & CS29544 flic & MJM477 & This study \\
\hline$\Delta f l a A$ & CS29544 flaA & MJM478 & This study \\
\hline$\triangle$ flaA pKD46 & CS29544 flaA harboring pKD46 & MJM480 & This study \\
\hline$\Delta$ flaA $\Delta$ flic & CS29544 flaAflic & MJM484 & This study \\
\hline$\Delta$ fliC/cfliC & CS29544 fliC/fliC complementation vector & MJM481 & This study \\
\hline Top10 & cfliC host strain & MJM423 & Invitrogen \\
\hline \multicolumn{4}{|l|}{ PLASMIDS } \\
\hline pCP20 & bla cat cl857 $\lambda \mathrm{P}_{\mathrm{R}}$ flp & & Cherepanov and Wackernagel, 1995 \\
\hline pKD3 & bla FRT cat FRT & & Datsenko and Wanner, 2000 \\
\hline pKD46 & bla $P_{\mathrm{BAD}}$ gam bet exo & & Datsenko and Wanner, 2000 \\
\hline cflic & $1 \mathrm{~kb}$ fragment flic native promoter and ORF cloned into pET-11a & pMJM49 & This study \\
\hline
\end{tabular}

TABLE 2 | Primer sequences used to create and confirm gene knockouts.

\begin{tabular}{|c|c|c|}
\hline Locus & Primers & Sequence $\left(5^{\prime}-3^{\prime}\right)$ \\
\hline \multirow[t]{2}{*}{ cat } & $\mathrm{c} 2 \_\mathrm{F}$ & GATCTTCCGTCACAGGTAGG \\
\hline & C1_R & TTATACGCAAGGCGACAAGG \\
\hline \multirow[t]{3}{*}{ flhA } & flhA_ko_F & ATCACCAAGGGTGCGGGGCGTATCGCGGAAGTGGGCGCGC \\
\hline & flhA_ko_R & GATAGGCTTCACCGCTGCCGATTTCCACGCCTTCATCAG \\
\hline & flhA_flank_F & GAAATCGGTCAGCAGATCC \\
\hline \multirow[t]{4}{*}{ fliG } & fliG_ko_F & TGACCATCGGTGAAGACCGCGCGGCGGAGGTGTTCAAACA \\
\hline & fliG_ko_R & ATAGCTTCTGTTCGTITCCACCTGAGACAGACGCACCG \\
\hline & fliG_flank_F & AGCGTAAAGAAGTGGAAGAG \\
\hline & fliG_flank_R & CGTCGACTTCTTCGCTTC \\
\hline motAB & motAB_ko_F & TGAACATCCTCGCCATAGCCAACAGCGGAAGGATGATGTC \\
\hline \multirow[t]{4}{*}{ flic } & fliC_ko_F & CAACCTGAACAAATCTCAGTCTGCTCTGGGCACTGCTATC \\
\hline & fliC_ko_F & GAAAGCTTGAGCGTCTATTAACGCAGCAGGGACAGCATGG \\
\hline & flic_flank_F & ATGCAGACGCAGGCTATTGAG \\
\hline & flic_flank_R & TCCGGCTATATCTGTCGCAAC \\
\hline \multirow[t]{4}{*}{ flaA } & flaA_ko_F & GCCACGCCGGTTGAGTCAGCGTCCGGGCAGGCGCGTGACG \\
\hline & flaA_ko_F & GCCTTGTTAACGACTCTCCGATGTGCGAAACGGCAACCCT \\
\hline & flaA_flank_F & СTTCCCGCTGACCATTTC \\
\hline & flaA_flank_R & AACGTGCCGTCCATATCC \\
\hline
\end{tabular}



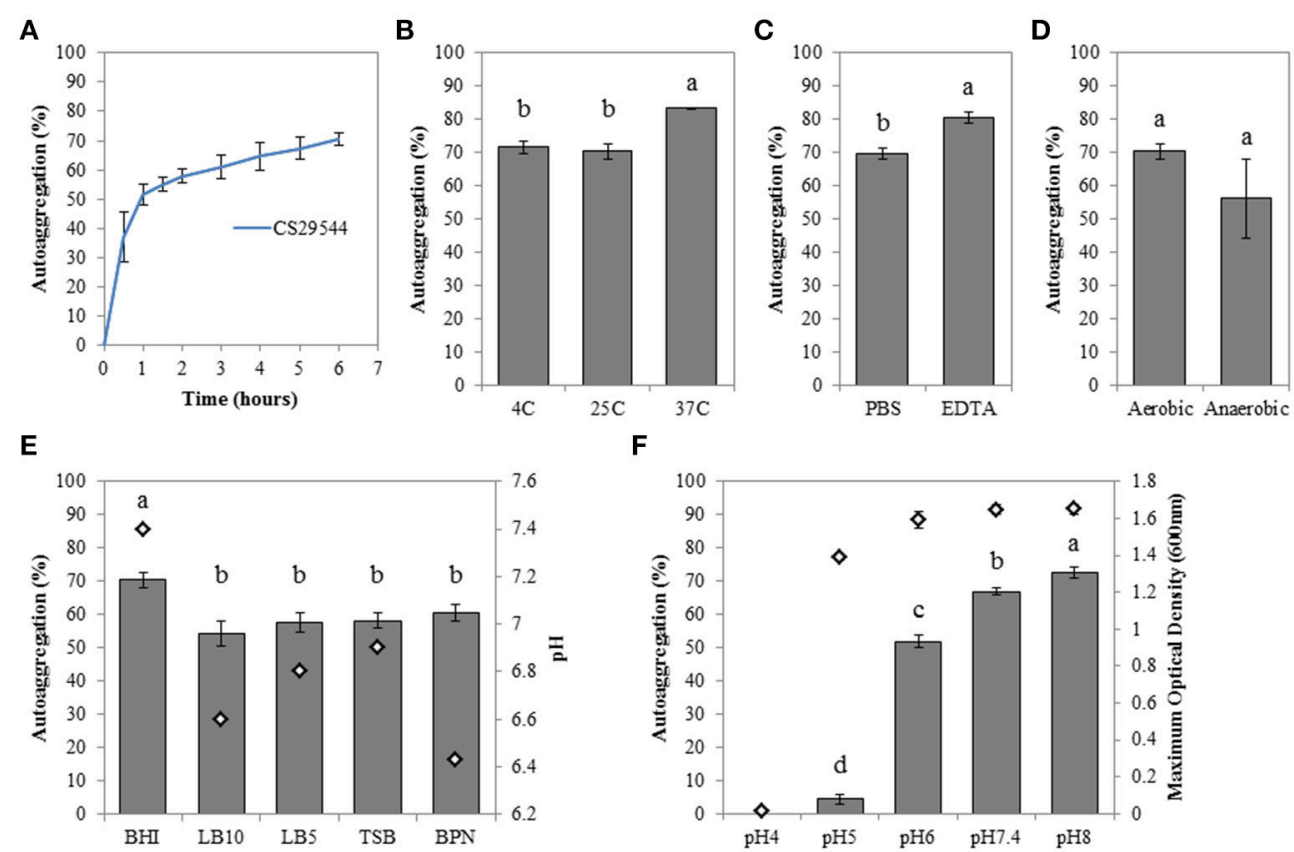

FIGURE 1 | Autoaggregation of stationary phase CS29544 cultures. (A) Time course of autoaggregation in BHI broth over 6 h. Maximum percent autoaggregation (B) in BHI broth during static incubation at different temperatures; (C) in BHI broth in the presence of 50 mM EDTA or PBS; (D) in BHI broth following growth aerobically or anaerobically; (E) in a variety of growth media; LB10 = LB Miller's formula (10 g/L NaCL), LB5 = LB Lennox's formula (5 g/L NaCL), TSB = tryptic soy broth and BPN = motility broth, initial $\mathrm{pH}$ of growth media is reported for reference; (F) in $\mathrm{BH}$ at different initial pH values. Maximum optical density (600 $\mathrm{nm}$; open diamonds) is reported for reference. All experiments are mean \pm standard error of three independent replicates. Values with no letters in common are significantly different $(P<0.05)$.

Beckman Institute's Microscopy Suite at the University of IllinoisUrbana Champaign. Briefly, the samples were stained with $2 \%$ uranyl acetate for $1 \mathrm{~min}$ and visualized using a CM200 LaB6 transmission electron microscope (FEI Co.). TEM was conducted at $120 \mathrm{kV}$ and images were captured with a $2 \mathrm{k} \times 2 \mathrm{k}$ digital camera (Tietz; Gauting; Germany). Several locations on the grids were examined, and the pictures were representative of the whole sample.

\section{Flagella Harvest and Filament Protein Identification, Sequencing, and In silico Analysis}

The extracellular protein fraction of CS29544, gene knockout, and complementation strains was harvested by differential centrifugation (DePamphilis and Adler, 1971). Bacteria were cultured in two baffled flasks each containing $500 \mathrm{~mL}$ of BHI and incubated overnight at $37^{\circ} \mathrm{C}$ with agitation $(250 \mathrm{rpm})$. Stationary phase cultures $(1 \mathrm{~L}$ total) were centrifuged at 3,220 $\times \mathrm{g}$ for 10 min at $4^{\circ} \mathrm{C}$. Bacterial pellets were resuspended in a total of 250 $\mathrm{mL} 0.1 \mathrm{M}$ Tris- $\mathrm{HCl}, \mathrm{pH} \mathrm{7.8}$, and blended at room temperature for $30 \mathrm{~s}$ at "whip" speed. Blended suspensions were centrifuged at $12,000 \times \mathrm{g}$ for $10 \mathrm{~min}$ at $4^{\circ} \mathrm{C}$. The supernatant was further ultracentrifuged at $55,000 \times \mathrm{g}$ for $1 \mathrm{~h}$ at $4^{\circ} \mathrm{C}$. Protein pellets were resuspended in a total of $1 \mathrm{~mL} 0.1 \mathrm{M}$ Tris- $\mathrm{HCl}, \mathrm{pH} 7.8$, containing $50 \%$ glycerol (v/v, protein storage buffer) and stored at $-20^{\circ} \mathrm{C}$. Total protein was quantified with the Bradford Assay
(BioRad Laboratories) and visualized with SDS-polyacrylamide gel electrophoresis. Typical flagellum protein recovery was $0.5-$ $0.7 \mathrm{mg} / \mathrm{mL}$ from $1 \mathrm{~L}$ of cell mass ( $\sim 10^{12}$ cells $)$.

The putative FliC $(28.9 \mathrm{kDa})$ band from CS29544 flagellum preparation was gel-excised and treated in-gel with trypsin (GBioscience) by the DNA Services group affiliated with the Roy J. Carver Biotechnology Center at the University of IllinoisUrbana Champaign. Protein was digested at a ratio of 1:20 (trypsin:protein) in $25 \mathrm{mM}$ ammonium bicarbonate at $55^{\circ} \mathrm{C}$ for $30 \mathrm{~min}$. Following lyophilization, peptides were analyzed by liquid chromatography-mass spectrometry. A total of 1-2 $\mu \mathrm{g}$ of digested peptides were loaded into a Dionex Ultimate 3000 RSLCnano connected directly to a Thermo LTQ-Velos-ETD Pro Mass Spectrometer (Thermo Fisher Scientific). Peptide were run on an Acclaim 300 C18 nano column (Thermo Fisher Scientific) using a gradient of $100 \% \mathrm{~A}$ (water $+0.1 \%$ formic acid) to $60 \%$ $\mathrm{B}$ (acetonitrile $+0.1 \%$ formic acid) at a flow rate of $300 \mathrm{~nL} / \mathrm{min}$. Raw data were collected by Xcalibur (Thermo Fisher Scientific) and processed with an in-house Mascot Distiller and Mascot Server (Matrix Science) and identified with the NCBInr database.

The secondary structure of the CS29544 FliC protein was predicted from the amino acid coding sequence (NCBI Reference Sequence: NZ_CP011047.1) using the Iterative Threading Assembly Refinement (I-TASSER) method (Yang and Zhang, 2015) with default parameters. The I-TASSER method is publically available at http://zhanglab.ccmb.med.umich.edu/ITASSER/, accessed 10/15/2015. The theoretical secondary 
structures of FliC were visualized and modified using UCSF Chimera v.1.10.2 (Pettersen et al., 2004), publically available at https://www.cgl.ucsf.edu/chimera/. The hydrophobicity index of the primary FliC amino acid sequence was determined using the ProtScale tool from the ExPASy Bioinformatics Resource Portal (Gasteiger et al., 2005), publically available at http://www. expasy.org/, accessed 06/01/2016. The hydrophobicity index was calculated using the Kyte and Doolittle amino acid scale (Kyte and Doolittle, 1982) with a window size of 15 amino acids.

\section{CS29544 and Flagellum Competition Assays}

A $3 \mathrm{~mL}$ aliquot of stationary phase CS29544 culture was mixed with detached flagellar pieces at a concentration of $0.1,1,5$, 10 , or $20 \mu \mathrm{g} / \mathrm{mL}$ of total flagellum protein and autoaggregated for $6 \mathrm{~h}$. Controls included adding $20 \mu \mathrm{g} / \mathrm{mL}$ of bovine serum albumin (BSA) or equal volume of protein storage buffer (no protein).

\section{CS29544 Biofilm Formation to Polyvinyl Chloride Tubing}

Polyvinyl chloride tubing (PVC; $0.318 \mathrm{~cm}$ outer diameter; 0.159 $\mathrm{cm}$ inner diameter; U.S. Plastic Corporation) was cut into $5 \mathrm{~cm}$ long pieces (external surface area $\sim 5.15 \mathrm{~cm}^{2}$ ) with a sterile blade. The PVC tube pieces were disinfected and submerged in $70 \%$ ethanol for $10 \mathrm{~min}$ and aseptically dried. Two PVC tube pieces were aseptically transferred to a $15 \mathrm{~mL}$ centrifuge tube containing $10 \mathrm{~mL}$ of BHI supplemented with $50 \mu \mathrm{g} / \mathrm{mL}$ ampicillin for the $\Delta f l i C / \mathrm{cfliC}$ strain. Each experimental vessel was inoculated with $1 \%(\mathrm{v} / \mathrm{v})$ stationary phase CS29544, $\Delta \operatorname{mot} A B, \Delta f l i C$, and $\triangle \mathrm{fliC} / \mathrm{cfliC}$ cells and incubated vertically at $37^{\circ} \mathrm{C}$ aerobically with agitation $(250 \mathrm{rpm}$ ) for $24 \mathrm{~h}$. After incubation, each PVC tube piece was transferred with sterile forceps and washed three times in $5 \mathrm{~mL}$ PBS, pH 7.4. After washing, each PVC tube piece was placed into $30 \mathrm{~mL}$ PBS, pH 7.4, containing $3 \mathrm{~g}$ of autoclaved $0.1 \mathrm{~mm}$ diameter glass beads (Research Products International). Biofilms were subsequently disrupted by vortex at maximum speed for $1 \mathrm{~min}$. Bacterial biofilm populations were enumerated by serial dilution $\left(10^{-1}-10^{-3}\right)$ in $0.1 \%$ peptone water, spreadplated $(0.1 \mathrm{~mL}$ in triplicate) on $\mathrm{BHI}$ agar plates, and incubated at $37^{\circ} \mathrm{C}$ overnight aerobically.

\section{Statistical Analysis}

Autoaggregation and biofilm formation assay results were from a minimum of three independent replicates. The differences between the mean maximum percent autoaggregation due to temperature, redox balance, $\mathrm{pH}$, blending, and various media; the differences between biofilm formation due to the presence of FliC were determined with SAS ${ }^{\circledR}$ (Version 9.4; SAS Institute) using the generalized linear model. When statistical significance was observed $(P<0.05)$, a post-hoc mean separation was run using Tukey's Honest Significance Difference test which controlled for unequal sample sizes. All data satisfied the assumptions of normality and homogeneity of variance.

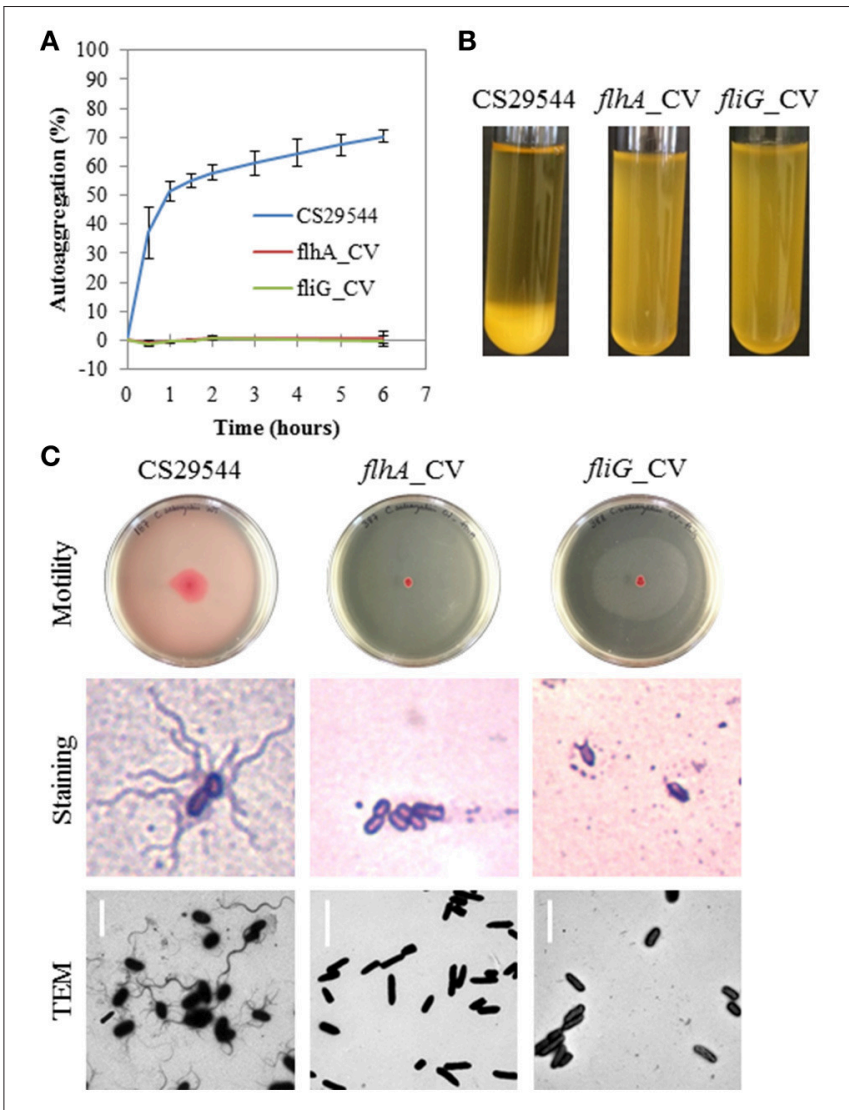

FIGURE 2 | Autoaggregation, motility and flagellation of nonautoaggregating CS29544. (A) Time course of autoaggregation in $\mathrm{BHI}$ broth over 6 h. CS29544 (included for reference) and clonal variants: flhA_CV and fliG_CV. Experiment is mean \pm standard error of three independent replicates. (B) Autoaggregation tube assays in $\mathrm{BH}$ broth after static incubation for 6 h. (C) Motility agar plates centrally inoculated and imaged after $24 \mathrm{~h}$, flagellation as detected by crystal violet staining at 1,000 $\times$ total magnification and TEM, bar $=4 \mu \mathrm{m}$.

\section{RESULTS}

\section{Characterization of Autoaggregation in CS29544}

Stationary phase BHI cultures of CS29544 autoaggregated at $25^{\circ} \mathrm{C}$ within 30-60 min (Figure 1A). Following $6 \mathrm{~h}$ static incubation, the maximum mean autoaggregation percentage was $70.3 \pm 2.2 \%$. Various growth media and physiological conditions were tested to better understand CS29544 autoaggregation. Autoaggregation of $\mathrm{BHI}$-grown cells at $37^{\circ} \mathrm{C}$ was significantly higher when statically incubated at $37^{\circ} \mathrm{C}$ than at 4 or $25^{\circ} \mathrm{C}$ $(P=0.0022$; Figure 1B) or in the presence of EDTA $(P=0.0092$; Figure 1C) compared to the PBS-added control. Although the maximum mean autoaggregation percentage was lower for cells grown in a reduced environment, the difference was not significant $(P=0.3003$, Figure 1D). Autoaggregation following overnight growth in $\mathrm{BHI}$ was significantly higher than overnight growth in LB10, LB5; TSB, and BPN ( $P=0.0203$; Figure 1E). The difference in autoaggregation was not readily explained by the presence of salt, extracts, protein sources, or inclusion of 


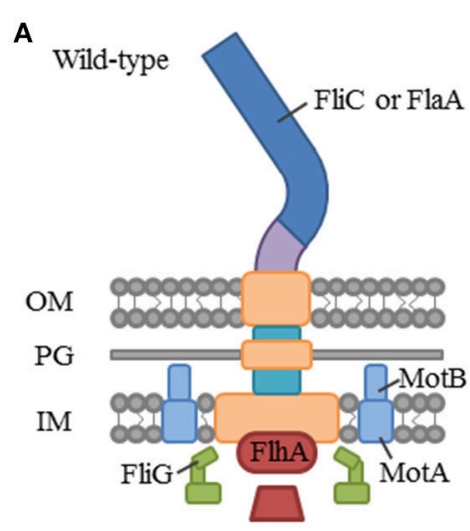

C

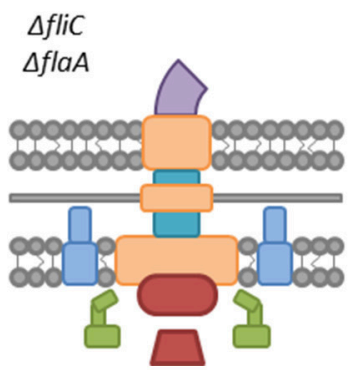

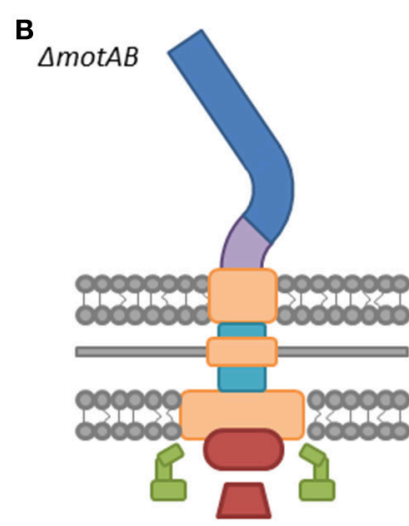

$\triangle f l h A$

$\Delta$ fliG

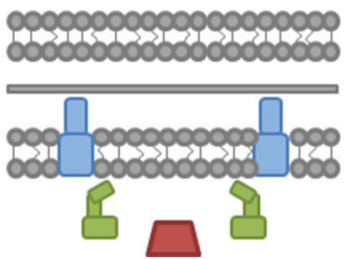

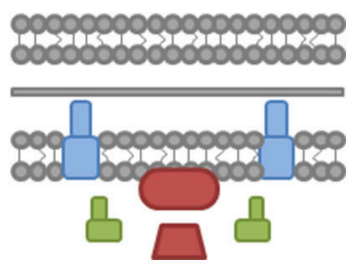

FIGURE 3 | Simplified diagram of the bacterial flagellum highlighting our gene knockout strategy. (A) Bacterial flagellum labeled with gene knockout targets. Filament proteins: FliC and FlaA, Stator (motor) proteins: MotA and MotB, C-ring protein: FliG, and Exporter apparatus protein: FlhA. (B) Hypothesized flagellum structure in the functional mutant: $\triangle$ motAB. (C) Hypothesized flagellum structure in the structural mutants: $\triangle$ fliC and $\triangle f l a A, \Delta f i h A$, and $\Delta$ fliG.

phosphates but rather the initial $\mathrm{pH}$ of the media. Therefore, CS29544 was grown in BHI with varying initial $\mathrm{pH}$ values (range pH 4-8). CS29544 did not grow at $\mathrm{pH} 4$, but its maximum growth was not affected by BHI from $\mathrm{pH}$ 5-8 (Figure 1F). As predicted, the maximum mean autoaggregation percentage decreased with decreasing $\mathrm{pH}(P<0.0001$; Figure 1F). The maximum mean autoaggregation percentage in $\mathrm{BHI}$ at an initial pH 6 was $51.9 \pm 1.6 \%$, which was slightly lower than the maximum mean autoaggregation percentage observed in the various media tested. During this initial characterization, an abolishment of autoaggregation was only achieved when grown in $\mathrm{BHI}$ at $\mathrm{pH} 5$; however, this observation did not clearly point to a specific mechanism. Since the maximum mean autoaggregation percentage never reached $100 \%$, we hypothesized that there might be a nonautoaggregating subpopulation of CS29544 mediated by an identifiable genetic variation.

\section{Nonautoaggregating CS29544 Are a Stable Genetically Distinct Subpopulation}

Following five successive passages selecting against autoaggregating CS29544, we were able to isolate two independent nonautoaggregating CVs of CS29544 (Figures 2A,B; see Movie S1 in the Supplementary Material). De novo assembly of the mate-pair library preparation from wildtype CS29544 was used as the reference genome for comparative genomic analysis with the nonautoaggregating CVs (2.10 and
3.6) assemblies. One unique single nucleotide polymorphism was detected in each of the nonautoaggregating CV. Strain 2.10 contained a putative deletion of two consecutive base pairs (GC), while strain 3.6 contained a putative deletion of a single base pair (C). Further corroboration by Sanger sequencing revealed the two nonautoaggregating CVs contained frameshift mutations, and NCBI BLAST analysis revealed that these mutations were located in the open reading frames of two flagellum proteins, FlhA (2.10) and FliG (3.6). Comparison with the full length wild-type FlhA and FliG proteins (692 and 340 amino acids, respectively) revealed that the frameshift mutations results in truncated proteins (157 and 183 amino acids, respectively). Strains carrying these variant mutations are referred to as flhA_CV (2.10) and fliG_CV (3.6), respectively. Accordingly, we assessed the flagellation of the wild-type CS29544, flhA_CV, and fliG_CV with motility assays and microscopy (Figure 2C). Both the flhA_CV and fliG_CV strains were nonmotile and aflagellate by staining and TEM (Figure $2 \mathrm{C}$ ). As a result, we constructed a variety of gene knockouts to determine if structurally intact and functional flagella were required for autoaggregation in CS29544.

\section{Flagellum Structure, Not Function, Is Required for Autoaggregation in CS29544}

Published C. sakazakii genomes, available from NCBI, have annotated some 40 genes related to their flagellum's structure, function, and regulation. Therefore, gene knockout strains 
(Table 1) were constructed to disrupt the structure and function of the CS29544 flagella (see Figures 3A-C for a simplified diagram of the bacterial flagella outlining our knockout strategy). Two basal body proteins, FlhA and FliG (same genes as the nonautoaggregating CVs) were targeted. Previously, FlhA truncation mutants in Campylobacter jejuni resulted in aflagellate cells lacking flagellar components past the inner membrane (Abrusci et al., 2013). FliG, along with FliN and FliM, forms the $\mathrm{C}$ ring of the basal body (Zhao et al., 2014). Proton-driven conformational changes in the MotA and MotB stator (motor) proteins (Kojima and Blair, 2001) directly interact with the $\mathrm{C}$ terminus of the FliG protein of the $\mathrm{C}$ ring to provide rotation to the flagella (Irikura et al., 1993; Lloyd et al., 1996). Although FliG is integral for the flagellum function, its necessity for assembly is disputed (Irikura et al., 1993; Lloyd et al., 1996). It was hypothesized that the disruption of $\operatorname{mot} A B$ would render the cells nonmotile while retaining the structural components. Additionally, the disruption of $f h A$ and $f l i G$ would block the early assembly of the flagella and the cells would be aflagellate. Based on the published CS29544 genome, CS29544 has redundant filament proteins; therefore, both FliC and FlaA single and double gene knockouts were constructed. Finally, the function of the flagella was disrupted by targeting the two motor proteins, MotA and MotB.

The $\triangle f l h A, \Delta f l i G, \Delta f l i C$, and $\triangle f l a A \Delta f l i C$ strains did not autoaggregate and were aflagellate by staining and TEM and nonmotile (Figures $4 \mathrm{~A}-\mathrm{C}$ ). Conversely, the $\triangle m o t A B$ and $\triangle$ flaA strains remained autoaggregative and had visible flagella by staining and TEM (Figures $4 \mathrm{~A}-\mathrm{C}$ ). These two strains differed in their motility: $\triangle$ flaA was motile while $\triangle \operatorname{mot} A B$ was not motile. Therefore, we concluded that motility was not required for autoaggregation in CS29544. Based on the phenotypes of the structural gene knockouts, we hypothesized that filaments composed of FliC, not FlaA, were required for autoaggregation. Upon mechanical removal of the filaments, only the autoaggregating CS29544, $\triangle \operatorname{mot} A B$, and $\triangle$ flaA strains possessed a dense $28.9 \mathrm{kDa}$ protein band (Figure 5). The band was confirmed as FliC by a total of five peptides with individual ion scores of 44 and a Mascot ion score of 1,191 (data not shown). Furthermore, the $\Delta f l i C$ strain did not contain a $50.1 \mathrm{kDa}$ band, which is the predicted size for FlaA. Autoaggregation phenotype, motility, and flagellation were restored in the $\Delta \mathrm{fliC} / \mathrm{cfliC}$

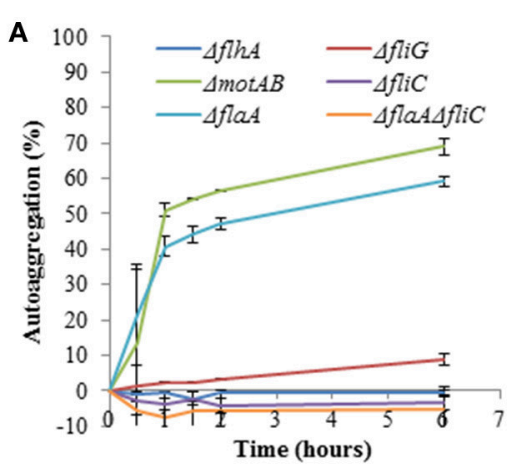

B

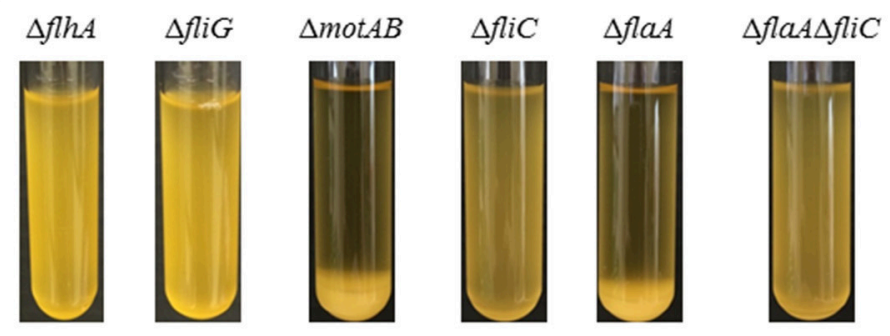

C $\quad \Delta f l h A$
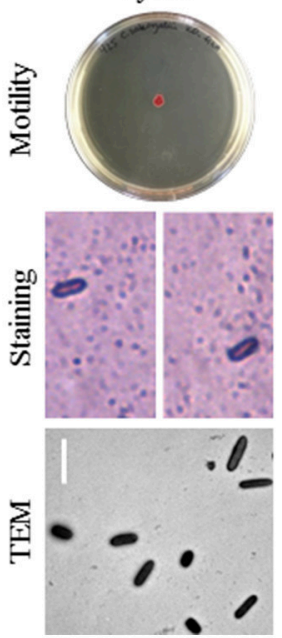
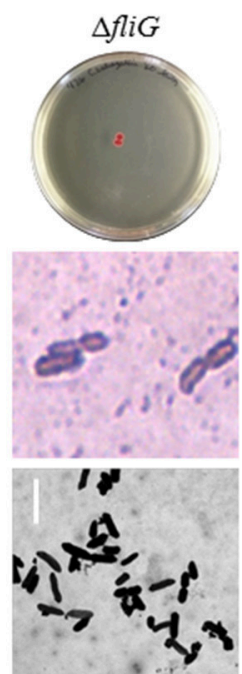
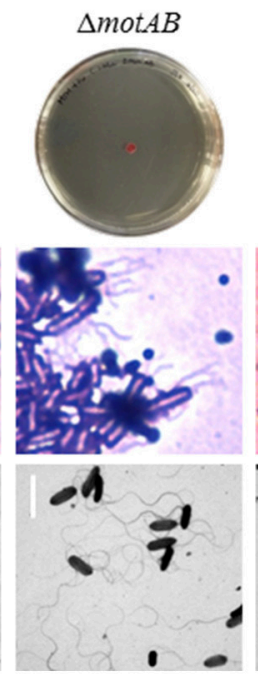
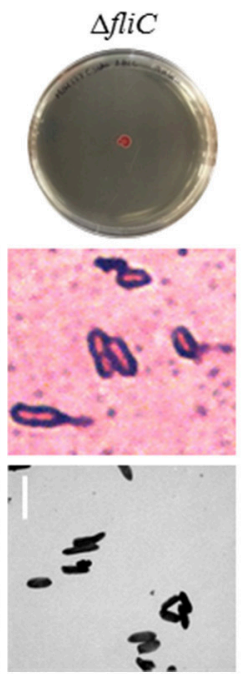

$\Delta f l a A$
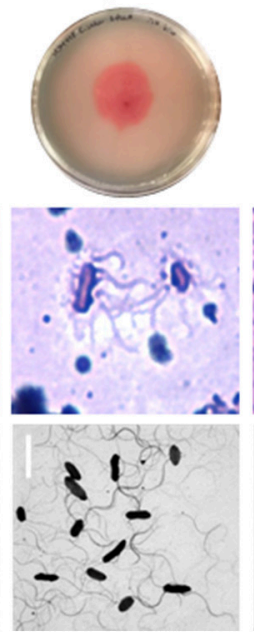
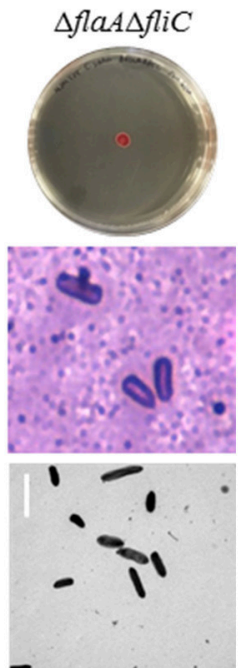

FIGURE 4 | Autoaggregation, motility, and flagellation of CS29544 and gene knockout strains. (A) Time course of autoaggregation in BHI broth over 6 h. Gene knockouts: $\Delta f / h A, \Delta f l i G, \Delta \operatorname{mot} A B, \Delta f l i C, \Delta f l a A, \Delta$ flaA $\Delta$ fliC. Experiment is mean \pm standard error of three independent replicates. (B) Autoaggregation tube assays in BHI broth after static incubation for $6 \mathrm{~h}$. (C) Motility agar plates centrally inoculated and imaged after $24 \mathrm{~h}$, flagellation as detected by crystal violet staining at $1,000 \times$ total magnification and TEM, bar $=4 \mu \mathrm{m}$. 


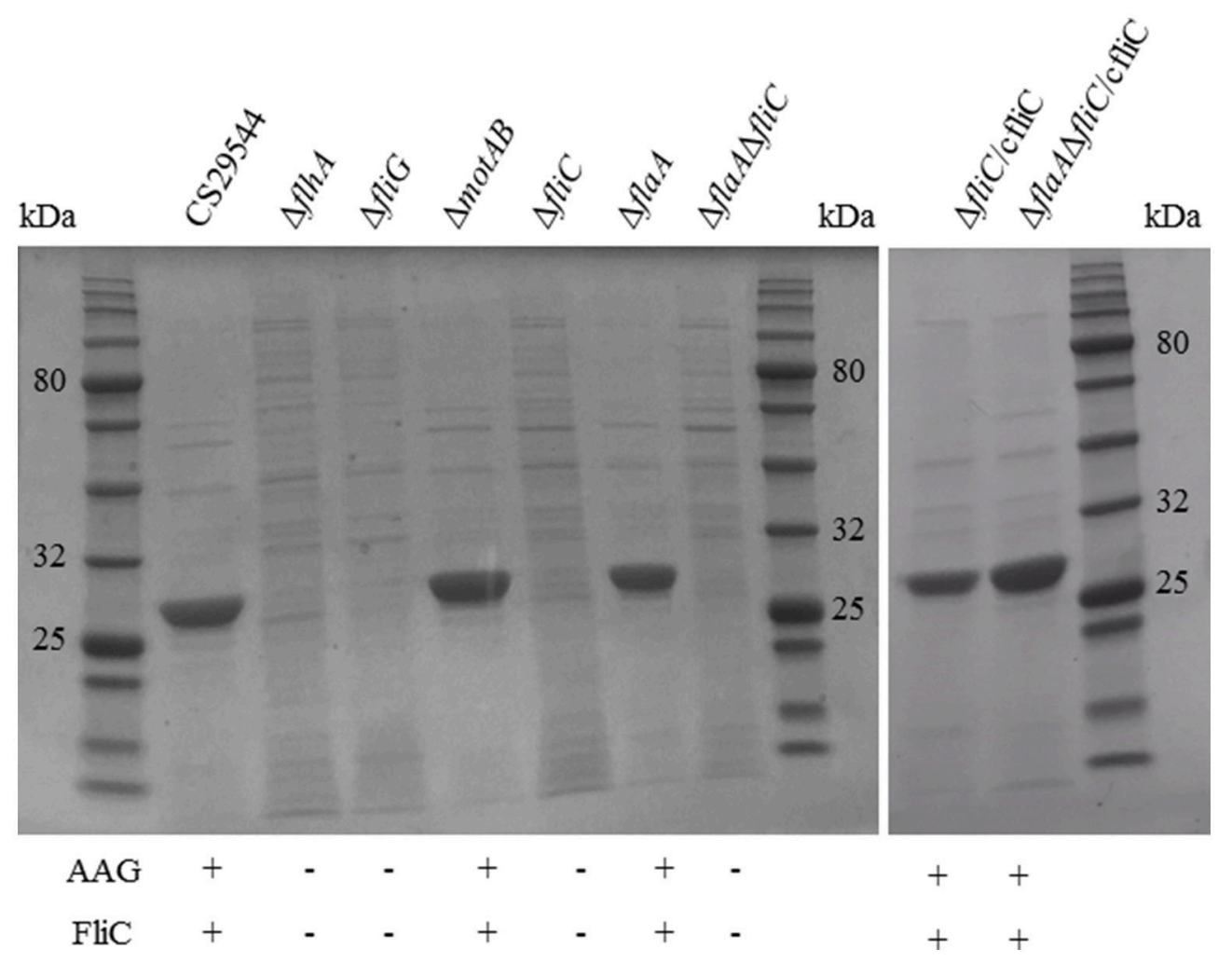

FIGURE 5 | Harvested filaments from of CS29544, gene knockout, and complementation strains. Gene knockouts: $\triangle$ flh $A, \Delta$ fliG, $\Delta m o t A B, \Delta f l i C, \Delta f l a A$, $\Delta$ flaA $\Delta$ fliC, and FliC complements: $\Delta$ fliC/cfliC and $\Delta$ flaA $\Delta$ fliC/cfliC. Each lane was loaded with $\sim 2 \mu \mathrm{g}$ of total protein. FliC expected size $28.9 \mathrm{kDa}$.

and $\Delta$ flaA $\Delta$ fliC/cfliC complementation strains (Figures 6A-C). Finally, we confirmed a loss of autoaggregation in CS29544 after mechanical removal of flagella from $79.4 \pm 4.4 \%$ to $2.2 \pm 2.2 \%$ with no reduction in cellular viability (data not shown).

\section{Flagella-Mediated Autoaggregation Occurs by Flagellum-Flagellum Interactions}

Visual analysis of the CS29544 TEM image revealed supercoiled flagella linking several bacteria together in a cluster (Figure 7A). Therefore, it was hypothesized that autoaggregation in CS29544 proceeds as flagella from one cell becomes entangled with the flagella from neighboring cells. To test this hypothesis, mechanically detached flagella pieces were added to stationary phase CS29544 cultures. Autoaggregation of CS29544 was not affected by adding 0.1 or $1.0 \mu \mathrm{g} / \mathrm{mL}$ of detached flagella, $20 \mu \mathrm{g} / \mathrm{mL}$ BSA, or the no-protein control (PSB; Figure 7B). Autoaggregation was prevented when $20 \mu \mathrm{g} / \mathrm{mL}$ of detached flagella were added. The addition of detached flagella altered the manner by which the CS29544 autoaggregated. The controls autoaggregated as before by forming small cell flocs that settled to the bottom of the tube. In the presence of 5 and $10 \mu \mathrm{g} / \mathrm{mL}$ of detached flagellum flocs did not form, rather a large mass of cells settled gradually to the bottom of the tube (see Movie S2 in the Supplementary Material).

The predicted secondary structure of the CS29544 FliC protein was analogous to homologous flagellins with a highly conserved flagellin $\mathrm{N}$ and $\mathrm{C}$ termini linked by a hypervariable region (Figure 8A). Analysis of the hydrophobicity scores of the linear amino acid sequence revealed a peak followed by a valley in hydrophobicity (Figure 8B) located in the hypervariable region of the CS29544 FliC. The bacterial filament is composed of several thousand flagellin proteins with the conserved regions stacked laterally. The hypervariable region is externally exposed and able to interact with its environment. We hypothesize that the hypervariable hydrophobic peaks and valleys of neighboring cells interact laterally to promote autoaggregation in CS29544. Further work will be required to test this hypothesis.

\section{Biofilm Formation on PVC Is Not Mediated by Flagella}

The total cellular population of wild-type CS29544 biofilms on PVC was $1.5 \times 10^{4} \pm 3.0 \times 10^{3} \mathrm{CFU} / \mathrm{cm}^{2}$. The total cellular populations of $\triangle \operatorname{mot} A B, \triangle \mathrm{fliC}$, and $\triangle \mathrm{fliC} / \mathrm{cfliC}$ on PVC biofilms were $4.8 \times 10^{3} \pm 2.2 \times 10^{3}, 2.4 \times 10^{4} \pm 7.0 \times 10^{3}$, and $1.0 \times 10^{4}$ $\pm 6.5 \times 10^{2} \mathrm{CFU} / \mathrm{cm}^{2}$, respectively. CS29544 biofilm formation on PVC was not mediated by FliC under the tested conditions $(P=0.0928$; Figure 9).

\section{DISCUSSION}

Although autoaggregation was demonstrated in C. sakazakii ATCC BAA_894 (Wang et al., 2012; Hu et al., 2015), the 

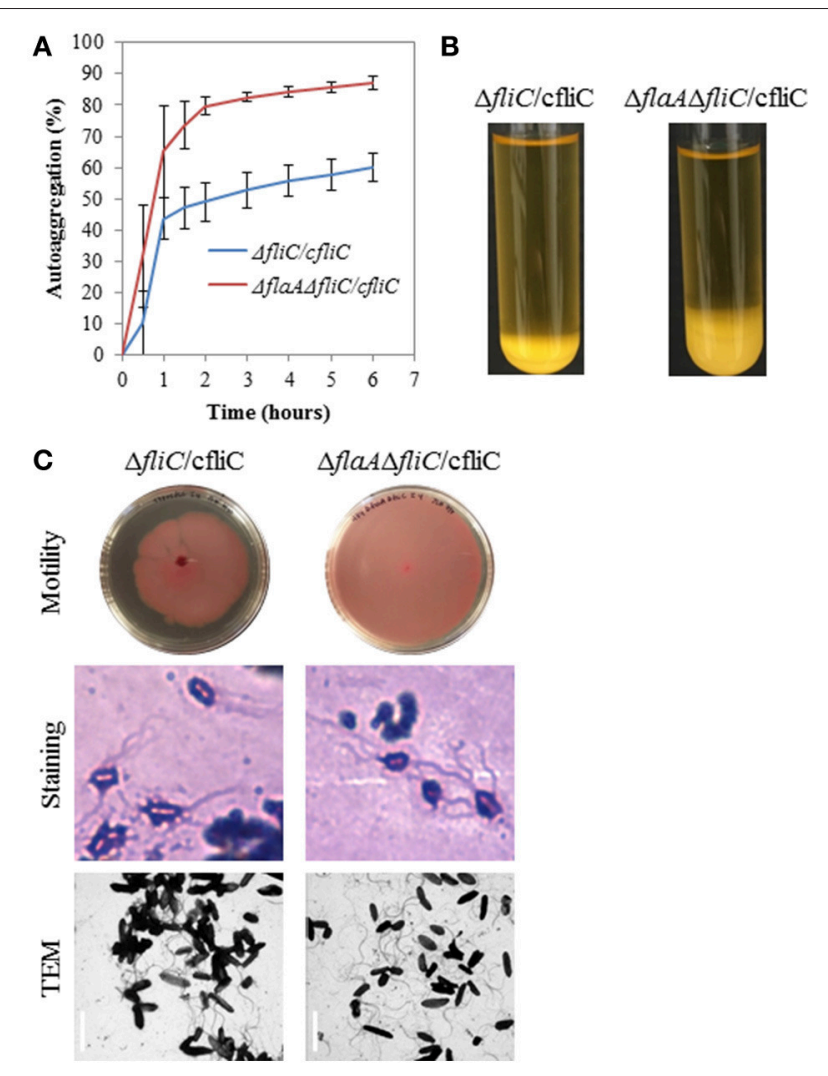

FIGURE 6 | Autoaggregation, motility, and flagellation of FliC complementation strains. (A) Time course of autoaggregation in $\mathrm{BHI}$ broth over $6 \mathrm{~h}$. FliC complements: $\Delta$ fliC/cfliC and $\Delta$ flaA $\Delta$ fliC/cfliC. Experiment is mean \pm standard error of three independent replicates. (B) Autoaggregation tube assays in $\mathrm{BHI}$ broth after static incubation for 6 h. (C) Motility agar plates centrally inoculated and imaged after $24 \mathrm{~h}$, flagellation as detected by crystal violet staining at 1,000 $\times$ total magnification and TEM, bar $=4 \mu \mathrm{m}$.

molecular basis for autoaggregation was not described. To understand the genetic determinants of autoaggregation in CS29544, a set of structural and functional flagellar mutants were constructed. These flagellar mutants revealed the requirement of FliC containing filaments in the autoaggregation of CS29544. Additionally, these results suggest an additional biological function for the CS29544 flagellum beyond motility.

Protein-protein interactions, such as flagella-mediated autoaggregation, may require specific environmental conditions. Previously, protein-protein aggregation in bacteria was influenced by altering the growth media (Girón et al., 1991), sodium chloride concentrations (Girard et al., 2010), pH (Sherlock et al., 2005; Alamuri et al., 2010), or the presence of divalent cations (Sjoblad et al., 1985; Abdel-Nour et al., 2014). In the present study, autoaggregation assays were conducted to identify nutritional dependencies and provide insights into potential mechanisms. Different growth media containing various nutrient extracts, protein sources, salts $(\mathrm{NaCl}$ and phosphates), and carbohydrates (dextrose) were tested. Additionally, autoaggregation was observed under a variety of temperatures, redox potentials, and $\mathrm{pH}$ values. Wild-type CS29544 was flagellated and highly motile under all tested growth conditions, except growth in $\mathrm{BHI}$ at $\mathrm{pH}$ 5. In hindsight, it is not surprising that autoaggregation in CS29544 had only minimal nutritional or conditional dependencies, even though flagellar expression is a tightly regulated system that quickly responds to changes in the surrounding bacterium environment (Osterman et al., 2015). Under favorable environmental conditions, such as nutrient-dense media, motility may be arrested following the downregulation of flagellar genes. However, nonmotile bacteria do not immediately shed their structurally intact flagella and these flagella can participate in other biological functions. Although abolishment of autoaggregation in CS29544 was observed in structural mutants $(\Delta f l h A, \Delta f l i G, \Delta f l i C$, and $\triangle f l a A \Delta f l i C$ ), autoaggregation was not affected in the functional mutant $(\triangle \operatorname{mot} A B)$ which retained the structural components. These results suggest that autoaggregation in CS29544 can serve as an additional biological function for the CS29544 flagellum under environmental conditions that favor the downregulation of motility but not the loss of structure. Of note, many other examples of autoaggregation in Enterobacteriaceae involve pili and fimbriae (Girón et al., 1991; Nataro et al., 1992; Collinson et al., 1993; Czeczulin et al., 1997; Schembri et al., 2001). While CS29544 has putative pilus and fimbrial genes, the present study did not identify a role for these structures in the autoaggregation of CS29544. Future studies are needed to investigate the role of pili and fimbriae in CS29544's pathogenicity.

The CS29544 genome encodes $>40$ genes that are required for the assembly, function, and regulation of its flagellum. In this study, autoaggregation was only mediated by the loss of structural proteins, specifically, the lack of the FliC containing filament. Four structural mutants, two direct $(\Delta f i C$ and $\triangle$ flaA $\triangle f l i C$ ) and two indirect $(\triangle f h A$ and $\triangle f l i G)$, resulted in aflagellate nonautoaggregating CS29544 cells. Since the extracellular filament, comprised of several thousand FliC monomers, extends several microns from the cell, it is physically able to promote cell-cell interactions. Upon close examination of wild-type CS29544 cells by TEM, neighboring cells appeared tethered by their filaments. Similar bundles were observed in Escherichia coli (Girón et al., 1991), Pseudomonas marina (Sjoblad et al., 1985), and Pyrococcus furiosus (Näther et al., 2006). Furthermore, flagella-mediated autoaggregation was disrupted in a dose-dependent manner by the addition of exogenous wild-type FliC filaments. Protein-protein interactions can be mediated by several factors, including ionic and hydrophobic bonds. As discussed above, only growth in $\mathrm{BHI}$ at $\mathrm{pH} 5$ abolished flagellamediated autoaggregation in CS29544 and no other nutritional or conditional dependencies were observed. Previously, TibAmediated autoaggregation in an enterotoxigenic E. coli was affected by changes in $\mathrm{pH}$ (Sherlock et al., 2005). The authors speculated that TibA-mediated autoaggregation might be promoted by $\mathrm{pH}$-mediated ionic bonds between charged amino acid side chains. It is tempting to conclude that flagella-mediated autoaggregation involves ionic bonding due to abolishment at pH 5; however, our observations do not support this conclusion. CS29544 cells grown in BHI at pH 5 were growth-impaired, had no visible flagella by staining, and were nonmotile by wet mount.

The CS29544 genome encodes two different flagellin proteins, fliC and flaA; however, only FliC monomers were incorporated 
A

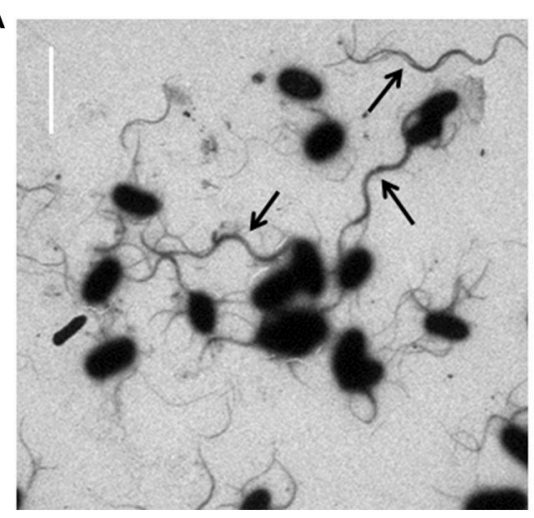

B

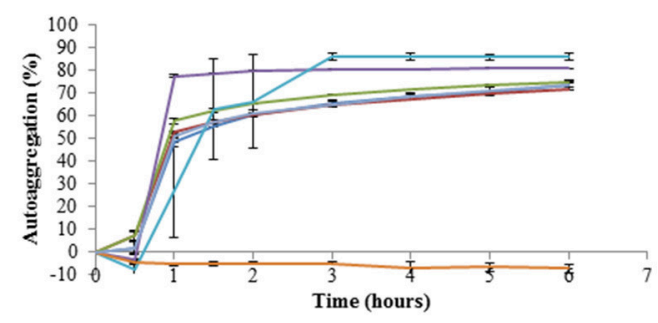

$-\mathrm{PSB} \quad-0.1 \mu \mathrm{g} / \mathrm{mL}-1 \mu \mathrm{g} / \mathrm{mL}-5 \mu \mathrm{g} / \mathrm{mL}$

FIGURE 7 | Autoaggregation competition assays with harvested filaments from CS29544. (A) CS29544 wild-type flagella TEM image, bar $=4 \mu \mathrm{m}$. Black arrows indicate bundles of flagella. (B) Time course of autoaggregation in BHI broth over $6 \mathrm{~h}$. Stationary phase CS29544 cultures combined with harvested FliC filaments $(0.1-20 \mu \mathrm{g} / \mathrm{mL}$ ), bovine serum albumin (BSA, $20 \mu \mathrm{g} / \mathrm{mL}$ ) and PSB (no protein control). Experiment is mean \pm standard error of three independent replicates.

A

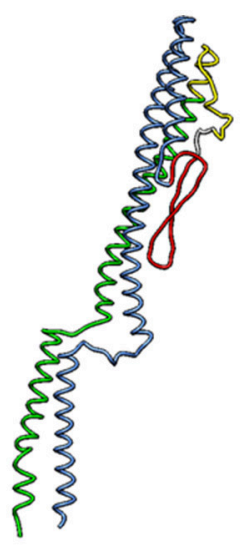

B

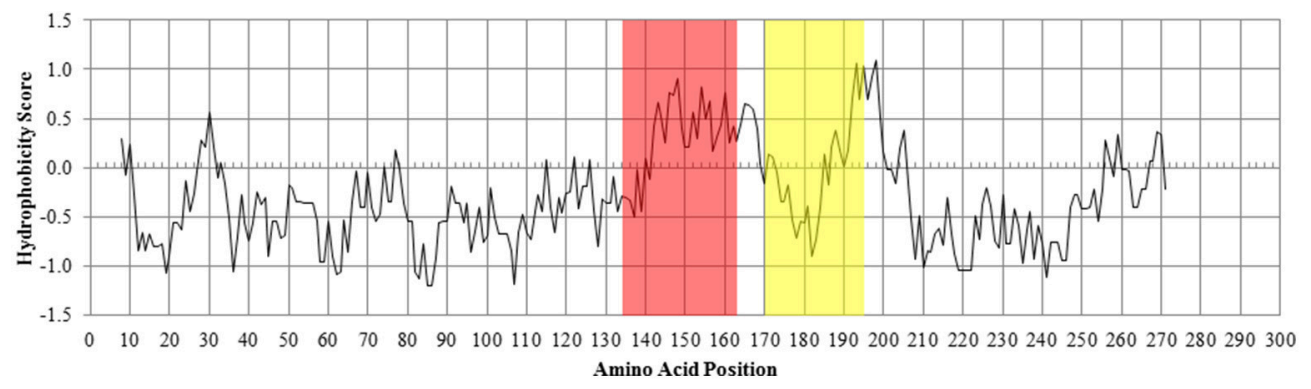

FIGURE 8 | In silico analysis of the CS29544 FliC protein. (A) Theoretical secondary structure of FliC from I-TASSER. Conserved regions: N terminus in blue, C terminus in green. Hypervariable region: hydrophobic peak in red, hydrophobic valley in yellow. (B) Hydrophobicity index along the linear amino acid sequence of Flic. Hydrophobic peak highlighted in red, hydrophobic valley highlighted in yellow.

into the harvested CS29544 filaments under the tested conditions. Consistent with this study, FliC is the sole C. sakazakii flagellin protein reported in the literature (Proudy et al., 2008; Cruz-Córdova et al., 2012). FliC flagellin proteins and their homologs have highly conserved $\mathrm{N}$ and $\mathrm{C}$ termini connected by a hypervariable region. The conserved domains of several flagellin proteins self-assemble and form the internal channel of the filament during elongation. The exposure of conserved domains to the bacterium's environment is limited and should not contribute to flagella-mediated autoaggregation. Conversely, the hypervariable region is invariably externally exposed and likely interacts with components of the bacterium's surroundings. As a result, our in silico methods were centered on the secondary structure and hydrophobicity of the hypervariable region. The entire CS29544 FliC flagellin protein is composed of 278 amino acids, of which 50 amino acids comprise the 


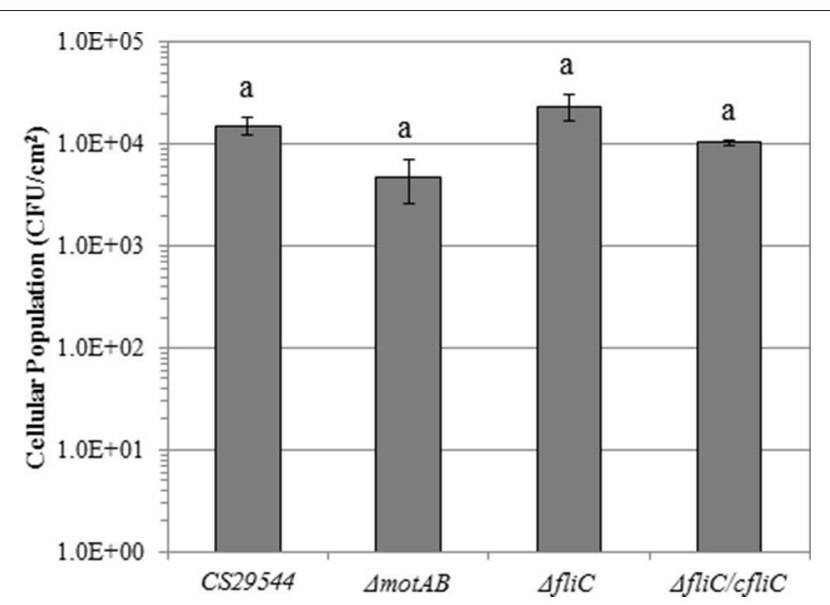

FIGURE 9 | Biofilm formation on polyvinyl chloride of CS29544 and select gene knockout and complementation strains. Experiment is mean \pm standard error of three independent replicates. Gene knockouts: $\triangle \operatorname{mot} A B$ and $\Delta$ fliC and FliC complement: $\Delta$ fliC /fliC. Values with no letters in common are significantly different $(P<0.05)$.

hypervariable region. Of note, the hypervariable region in the C. sakazakii FliC flagellin protein is far shorter than FliC flagellin proteins of related Enterobacteriaceae (Proudy et al., 2008). As seen in the predicted secondary structure, the hypervariable region is relaxed and spatially aligned with the conserved regions. Unfortunately, the predicted FliC secondary structure did not reveal any obvious structural contributions to flagellamediated autoaggregation. Rather, alterations in hydrophobicity along the amino acid sequence illustrated the potential of hydrophobic interactions. It is hypothesized that there are, along the length of every filament, thousands of FliC monomers with alternating hydrophobic peaks and valleys (colored in red and yellow, respectively, in Figure 8A). The following hypothesis can be best exemplified by the dimerization of proteins by the leucine zipper motif. When filaments are in close proximity, it is hypothesized that these hydrophobic peaks and valleys interact to allow rapid and reversible supercoiling. Once a sufficient number of CS29544 cells are tethered together by their FliC filaments, autoaggregation by this mechanism proceeds. Further work is needed to test these hypotheses and to more precisely define which amino acids interact during flagella-mediated autoaggregation in CS29544.

C. sakazakii strains form biofilms on a variety of abiotic surfaces, including stainless steel (Iversen et al., 2004; Kim et al., 2006; Jung et al., 2013), silicon (Iversen et al., 2004), latex (Iversen et al., 2004), PVC (Lehner et al., 2005; Kim et al., 2006; Hurrell et al., 2009a), and polyurethane (Hurrell et al., 2009a). The latter two plastics are used for enteral feeding tubes and formation of C. sakazakii biofilms on these plastics is of concern. Hurrell et al. (2009b) isolated C. sakazakii, along with other pathogenic Enterobacteriaceae from used enteral feeding tubes. Biofilm formation on enteral feeding tubes is problematic for several reasons. First, enteral feeding tubes typically reside within an infant at body temperature $\left(37^{\circ} \mathrm{C}\right)$ for several days (Mehall et al.,
2002). Secondly, infant feeds are nutrient-dense and provide sufficient growth substrate for bacteria. Lastly, with every feeding, bacteria might dislodge from the biofilm and continuously inoculate the neonate (Mehall et al., 2002; Hurrell et al., 2009b). To determine the impact of flagella-mediated autoaggregation on C. sakazakii biofilm formation, the biofilm formation by the wild-type CS29544 was compared to the $\triangle \operatorname{mot} A B, \Delta f l i C$, and $\triangle f l i C / c f l i C$ strains. To model C. sakazakii biofilm formation on neonatal enteral feeding tubes, flagella-mediated biofilm formation was tested in a nutrient-dense environment (BHI broth) at $37^{\circ} \mathrm{C}$ using PVC tubing. In the present study, the total cellular biofilm population on PVC tubing ranged from 3.7-log $\mathrm{CFU} / \mathrm{cm}^{2}$ in the $\triangle m o t A B$ strain to $4.4-\log \mathrm{CFU} / \mathrm{cm}^{2}$ in the $\Delta f i C$ strain. There was no significant difference in biofilm formation between the wild-type CS29544 and the $\triangle \operatorname{motAB}, \Delta f l i C$, and $\triangle \mathrm{fliC} / \mathrm{cfliC}$ strains under the tested conditions. The observed C. sakazakii population density was consistent with the mean biofilm population of $4.0-\log \mathrm{CFU} / \mathrm{cm}^{2}$ on PVC tubing of five C. sakazakii strains grown in TSB at $12^{\circ} \mathrm{C}$ reported by Kim et al. (2006). Additionally, that study reported an approximate 1.5$\log$ increase in the mean biofilm population $\left(5.7-\log \mathrm{CFU} / \mathrm{cm}^{2}\right.$ ) on PVC tubing when C. sakazakii strains were grown in TSB at $25^{\circ} \mathrm{C}$. Given that $27^{\circ} \mathrm{C}$ is the optimal temperature for C. sakazakii exopolysaccharide production, this result is not surprising. Admittedly, C. sakazakii biofilm formation due to differences in flagella-mediated autoaggregation phenotype was not robustly tested. To date, a single study has demonstrated the importance of C. sakazakii strain ES5 flagellum in biofilm formation and adhesion to microtiter plates (Hartmann et al., 2010). The data presented in the present study demonstrates that additional research into $C$. sakazakii flagella-mediated autoaggregation, biofilm formation, and gastrointestinal colonization is critically needed.

A significant shortcoming of this study is its limited scope. A single strain of C. sakazakii was characterized, and generalization to all C. sakazakii strains should be avoided. Currently, our collective understanding of $C$. sakazakii pathogenesis is insufficient. Several decades of work were completed to characterize the diverse pathotypes in E. coli, and it is tempting to speculate that C. sakazakii may have definable pathotypes of which flagella-mediated autoaggregation is important. Future studies should be designed to characterize flagella-mediated autoaggregation contributions to $C$. sakazakii pathogenesis in vivo with suitable animal models. Concurrently, autoaggregation, not necessarily flagella-mediated, should be characterized in several clinical, environmental, and laboratory C. sakazakii strains. The present study contributes much-needed knowledge to the C. sakazakii literature.

\section{AUTHOR CONTRIBUTIONS}

$\mathrm{JH}$ conceived of the project, contributed to the design of the experimental methods, led the acquisition, analysis, and interpretation of the data other than experiments completed by the acknowledged collaborators, wrote initial and revised drafts of the manuscript, and approved the final manuscript 
submission. MM contributed to project design, selection of experimental methods, interpretation of data throughout the project, contributed to drafting and revising of the manuscript, approved the final manuscript submission. $\mathrm{JH}$ and $\mathrm{MM}$ agree to be accountable for the work detailed in the final manuscript submission.

\section{FUNDING}

$\mathrm{JH}$ was supported by the Agnes and Bill Brown Fellowship in Microbiology from the University of Illinois-Urbana Champaign. This research received no direct financial support from any funding agency in the public, commercial, or not-for-profit sectors.

\section{REFERENCES}

Abdel-Nour, M., Duncan, C., Prashar, A., Rao, C., Ginevra, C., Jarraud, S., et al. (2014). The Legionella pneumophila collagen-like protein mediates sedimentation, autoaggregation, and pathogen-phagocyte interactions. Appl. Environ. Microbiol. 80, 1441-1454. doi: 10.1128/AEM.03254-13

Abrusci, P., Vergara-Irigaray, M., Johnson, S., Beeby, M. D., Hendrixson, D. R., Roversi, P., et al. (2013). Architecture of the major component of the type III secretion system export apparatus. Nat. Struct. Mol. Biol. 20, 99-104. doi: $10.1038 / \mathrm{nsmb} .2452$

Alamuri, P., Löwer, M., Hiss, J. A., Himpsl, S. D., Schneider, G., and Mobley, H. L. T. (2010). Adhesion, invasion, and agglutination mediated by two trimeric autotransporters in the human uropathogen Proteus mirabilis. Infect. Immun. 78, 4882-4894. doi: 10.1128/IAI.00718-10

An, Y. H., and Friedman, R. J. (1998). Concise review of mechanisms of bacterial adhesion to biomaterial surfaces. J. Biomed. Mater. Res. 43, 338-348.

Arenas, J., Cano, S., Nijland, R., van Dongen, V., Rutten, L., van der Ende, A., et al. (2015). The meningococcal autotransporter AutA is implicated in autoaggregation and biofilm formation. Environ. Microbiol. 17, 1321-1337. doi: 10.1111/1462-2920.12581

Axelrod, D., Kazmerski, K., and Iyer, K. (2006). Pediatric enteral nutrition. JPEN J. Parenter. Enteral Nutr. 30, S21-S26. doi: 10.1177/01486071060300S1S21

Bai, L., Xia, S., Lan, R., Liu, L., Ye, C., Wang, Y., et al. (2012). Isolation and characterization of cytotoxic, aggregative Citrobacter freundii. PLoS ONE 7:e33054. doi: 10.1371/journal.pone.0033054

Biering, G., Karlsson, S., Clark, N. C., Jónsdóttir, K. E., Lúdvígsson, P., and Steingrímsson, O. (1989). Three cases of neonatal meningitis caused by Enterobacter sakazakii in powdered milk. J. Clin. Microbiol. 27, 2054-2056.

Breeuwer, P., Lardeau, A., Peterz, M., and Joosten, H. M. (2003). Desiccation and heat tolerance of Enterobacter sakazakii. J. Appl. Microbiol. 95, 967-973. doi: 10.1046/j.1365-2672.2003.02067.x

Broge, T., and Lee, A. (2013). A case of cronobacter (Enterobacter sakazakii) bacteremia in a breastfed infant. J. Pediatr. Infect. Dis. Soc. 2, e1-e2. doi: $10.1093 /$ jpids/pit021

Cherepanov, P. P., and Wackernagel, W. (1995). Gene disruption in Escherichia coli: $\mathrm{TcR}$ and $\mathrm{KmR}$ cassettes with the option of Flp-catalyzed excision of the antibiotic-resistance determinant. Gene 158, 9-14. doi: 10.1016/0378-1119(95)00193-A

Collinson, S. K., Doig, P. C., Doran, J. L., Clouthier, S., Trust, T. J., and Kay, W. W. (1993). Thin, aggregative fimbriae mediate binding of Salmonella enteritidis to fibronectin. J. Bacteriol. 175, 12-18. doi: 10.1128/jb.175.1.12-18.1993

Costerton, J. W., Cheng, K. J., Geesey, G. G., Ladd, T. I., Nickel, J. C., Dasgupta, M., et al. (1987). Bacterial biofilms in nature and disease. Annu. Rev. Microbiol. 41, 435-464. doi: 10.1146/annurev.mi.41.100187.002251

Cruz-Córdova, A., Rocha-Ramírez, L. M., Ochoa, S. A., González-Pedrajo, B., Gónzalez-Pedrajo, B., Espinosa, N., et al. (2012). Flagella from five Cronobacter species induce pro-inflammatory cytokines in macrophage derivatives from human monocytes. PLoS ONE 7:e52091. doi: 10.1371/journal.pone.0052091

\section{ACKNOWLEDGMENTS}

We acknowledge the assistance of staff of the DNA and Protein Services Lab at the Roy J. Carver Biotechnology Center and the Beckman Institute Microscopy Suite, particularly Catherine Wallace. We thank Dr. James Slauch for the Lambda Red Recombinase System and Daniel Hoeflinger for compiling the time lapse photos into videos.

\section{SUPPLEMENTARY MATERIAL}

The Supplementary Material for this article can be found online at: http://journal.frontiersin.org/article/10.3389/fmicb. 2017.00301/full\#supplementary-material

Czeczulin, J. R., Balepur, S., Hicks, S., Phillips, A., Hall, R., Kothary, M. H., et al. (1997). Aggregative adherence fimbria II, a second fimbrial antigen mediating aggregative adherence in enteroaggregative Escherichia coli. Infect. Immun. 65, 4135-4145.

Datsenko, K. A., and Wanner, B. L. (2000). One-step inactivation of chromosomal genes in Escherichia coli K-12 using PCR products. Proc. Natl. Acad. Sci. U.S.A. 97, 6640-6645. doi: 10.1073/pnas.120163297

DePamphilis, M. L., and Adler, J. (1971). Purification of intact flagella from Escherichia coli and Bacillus subtilis. J. Bacteriol. 105, 376-383.

Donnenberg, M. S., and Kaper, J. B. (1991). Construction of an eae deletion mutant of enteropathogenic Escherichia coli by using a positive-selection suicide vector. Infect. Immun. 59, 4310-4317.

Favre-Bonte, S., Darfeuille-Michaud, A., and Forestier, C. (1995). Aggregative adherence of Klebsiella pneumoniae to human intestine-407 cells. Infect. Immun. 63, 1318-1328.

Gao, Z. P., Nie, P., Lu, J. F., Liu, L. Y., Xiao, T. Y., Liu, W., et al. (2015). Type III secretion system translocon component eseb forms filaments on and mediates autoaggregation of and biofilm formation by Edwardsiella tarda. Appl. Environ. Microbiol. 81, 6078-6087. doi: 10.1128/AEM.01254-15

Gasteiger, E., Hoogland, C., Gattiker, A., Duvaud, S., Wilkins, M., Appel, R., et al. (2005). "Protein identification and analysis tools on the ExPASy server," in The Proteomics Protocols Handbook, ed J. Walker (Totowa, NJ: Humana Press), 571-607. doi: 10.1385/1-59259-890-0:571 [Accessed November 20, 2016].

Girard, V., Côté, J.-P., Charbonneau, M.-E., Campos, M., Berthiaume, F., Hancock, M. A., et al. (2010). Conformation change in a self-recognizing autotransporter modulates bacterial cell-cell interaction. J. Biol. Chem. 285, 10616-10626. doi: 10.1074/jbc.M109.069070

Girón, J. A., Ho, A. S., and Schoolnik, G. K. (1991). An inducible bundleforming pilus of enteropathogenic Escherichia coli. Science 254, 710-713. doi: $10.1126 /$ science. 1683004

Haiko, J., and Westerlund-Wikström, B. (2013). The role of the bacterial flagellum in adhesion and virulence. Biology 2, 1242-1267. doi: 10.3390/biology 2041242

Hartmann, I., Carranza, P., Lehner, A., Stephan, R., Eberl, L., and Riedel, K. (2010). Genes involved in Cronobacter sakazakii biofilm formation. Appl. Environ. Microbiol. 76, 2251-2261. doi: 10.1128/AEM.00 930-09

Hu, L., Grim, C. J., Franco, A. A., Jarvis, K. G., Sathyamoorthy, V., Kothary, M. H., et al. (2015). Analysis of the cellulose synthase operon genes, bcsA, bcsB, and bcsC in Cronobacter species: prevalence among species and their roles in biofilm formation and cell-cell aggregation. Food Microbiol. 52, 97-105. doi: 10.1016/j.fm.2015.07.007

Hurrell, E., Kucerova, E., Loughlin, M., Caubilla-Barron, J., and Forsythe, S. J. (2009a). Biofilm formation on enteral feeding tubes by Cronobacter sakazakii, Salmonella serovars and other Enterobacteriaceae. Int. J. Food Microbiol. 136, 227-231. doi: 10.1016/j.ijfoodmicro.2009.08.007

Hurrell, E., Kucerova, E., Loughlin, M., Caubilla-Barron, J., Hilton, A., Armstrong, R., et al. (2009b). Neonatal enteral feeding tubes as loci for 
colonisation by members of the Enterobacteriaceae. BMC Infect. Dis. 9:146. doi: 10.1186/1471-2334-9-146

Irikura, V. M., Kihara, M., Yamaguchi, S., Sockett, H., and Macnab, R. M. (1993). Salmonella typhimurium fliG and fliN mutations causing defects in assembly, rotation, and switching of the flagellar motor. J. Bacteriol. 175, 802-810. doi: $10.1128 /$ jb.175.3.802-810.1993

Iversen, C., Lane, M., and Forsythe, S. J. (2004). The growth profile, thermotolerance and biofilm formation of Enterobacter sakazakii grown in infant formula milk. Lett. Appl. Microbiol. 38, 378-382. doi: 10.1111/j.1472-765X.2004.01507.x

Iversen, C., Mullane, N., McCardell, B., Tall, B. D., Lehner, A., Fanning, S., et al. (2008). Cronobacter gen. nov., a new genus to accommodate the biogroups of Enterobacter sakazakii, and proposal of Cronobacter sakazakii gen. nov., comb. nov., Cronobacter malonaticus sp. nov., Cronobacter turicensis sp. nov., Cronobacter muytjensii sp. nov., Cronobacter dublinensis sp. nov., Cronobacter genomospecies 1, and of three subspecies, Cronobacter dublinensis subsp. dublinensis subsp. nov., Cronobacter dublinensis subsp. lausannensis subsp. nov. and Cronobacter dublinensis subsp. lactaridi subsp. nov. Int. J. Syst. Evol. Microbiol. 58, 1442-1447. doi: 10.1099/ijs.0.65577-0

Jason, J. (2012). Prevention of invasive Cronobacter infections in young infants fed powdered infant formulas. Pediatrics 130, e1076-e1084. doi: $10.1542 /$ peds.2011-3855

Jung, J.-H., Choi, N.-Y., and Lee, S.-Y. (2013). Biofilm formation and exopolysaccharide (EPS) production by Cronobacter sakazakii depending on environmental conditions. Food Microbiol. 34, 70-80. doi: $10.1016 /$ j.fm.2012.11.008

Kim, H., Ryu, J.-H., and Beuchat, L. R. (2006). Attachment of and biofilm formation by Enterobacter sakazakii on stainless steel and enteral feeding tubes. Appl. Environ. Microbiol. 72, 5846-5856. doi: 10.1128/AEM.00654-06

Kojima, S., and Blair, D. F. (2001). Conformational change in the stator of the bacterial flagellar motor. Biochemistry (Mosc.) 40, 13041-13050. doi: 10.1021/bi011263o

Kyte, J., and Doolittle, R. F. (1982). A simple method for displaying the hydropathic character of a protein. J. Mol. Biol. 157, 105-132. doi: 10.1016/0022-2836(82)90515-0

Lai, K. K. (2001). Enterobacter sakazakii infections among neonates, infants, children, and adults. Case reports and a review of the literature. Medicine (Baltimore) 80, 113-122. doi: 10.1097/00005792-200103000-00004

Lehner, A., Riedel, K., Eberl, L., Breeuwer, P., Diep, B., and Stephan, R. (2005). Biofilm formation, extracellular polysaccharide production, and cell-to-cell signaling in various Enterobacter sakazakii strains: aspects promoting environmental persistence. J. Food Prot. 68, 2287-2294. doi: 10.4315/0362-028X-68.11.2287

Lloyd, S. A., Tang, H., Wang, X., Billings, S., and Blair, D. F. (1996). Torque generation in the flagellar motor of Escherichia coli: evidence of a direct role for FliG but not for FliM or FliN. J. Bacteriol. 178, 223-231. doi: $10.1128 /$ jb.178.1.223-231.1996

Martin, M. (2011). Cutadapt removes adapter sequences from high-throughput sequencing reads. EMBnet. J. 17, 10-12. doi: 10.14806/ej.17.1.200

Mehall, J. R., Kite, C. A., Saltzman, D. A., Wallett, T., Jackson, R. J., and Smith, S. D. (2002). Prospective study of the incidence and complications of bacterial contamination of enteral feeding in neonates. J. Pediatr. Surg. 37, 1177-1182. doi: 10.1053/jpsu.2002.34467

Nakao, R., Ramstedt, M., Wai, S. N., and Uhlin, B. E. (2012). Enhanced biofilm formation by Escherichia coli LPS mutants defective in Hep biosynthesis. PLoS ONE 7:e51241. doi: 10.1371/journal.pone.0051241

Nataro, J. P., Deng, Y., Maneval, D. R., German, A. L., Martin, W. C., and Levine, M. M. (1992). Aggregative adherence fimbriae I of enteroaggregative Escherichia coli mediate adherence to HEp-2 cells and hemagglutination of human erythrocytes. Infect. Immun. 60, 2297-2304.

Näther, D. J., Rachel, R., Wanner, G., and Wirth, R. (2006). Flagella of Pyrococcus furiosus: multifunctional organelles, made for swimming, adhesion to various surfaces, and cell-cell contacts. J. Bacteriol. 188, 6915-6923. doi: 10.1128/JB.00527-06

Osaili, T. M., Shaker, R. R., Al-Haddaq, M. S., Al-Nabulsi, A. A., and Holley, R. A. (2009). Heat resistance of Cronobacter species (Enterobacter sakazakii) in milk and special feeding formula. J. Appl. Microbiol. 107, 928-935. doi: $10.1111 /$ j.1365-2672.2009.04271.x
Osterman, I. A., Dikhtyar, Y. Y., Bogdanov, A. A., Dontsova, O. A., and Sergiev, P. V. (2015). Regulation of flagellar gene expression in bacteria. Biochem. Biokhimiia 80, 1447-1456. doi: 10.1134/S00062979151 1005X

Pettersen, E. F., Goddard, T. D., Huang, C. C., Couch, G. S., Greenblatt, D. M., Meng, E. C., et al. (2004). UCSF Chimera-a visualization system for exploratory research and analysis. J. Comput. Chem. 25, 1605-1612. doi: 10.1002/jcc. 20084

Prigent-Combaret, C., Prensier, G., Le Thi, T. T., Vidal, O., Lejeune, P., and Dorel, C. (2000). Developmental pathway for biofilm formation in curli-producing Escherichia coli strains: role of flagella, curli and colanic acid. Environ. Microbiol. 2, 450-464. doi: 10.1046/j.1462-2920.2000. 00128.x

Proudy, I., Bouglé, D., Coton, E., Coton, M., Leclercq, R., and Vergnaud, M. (2008). Genotypic characterization of Enterobacter sakazakii isolates by PFGE, BOX-PCR and sequencing of the fliC gene. J. Appl. Microbiol. 104, 26-34. doi: 10.1111/j.1365-2672.2007.03526.x

Ravisankar, S., Syed, S. S., Garg, P., and Higginson, J. (2014). Is Cronobacter sakazakii infection possible in an exclusively breastfed premature neonate in the neonatal intensive care unit? J. Perinatol. Off. J. Calif. Perinat. Assoc. 34, 408-409. doi: 10.1038/jp.2014.14

Riedel, K., and Lehner, A. (2007). Identification of proteins involved in osmotic stress response in Enterobacter sakazakii by proteomics. Proteomics 7, 1217-1231. doi: 10.1002/pmic.200600536

Rocha, S. P. D., Elias, W. P., Cianciarullo, A. M., Menezes, M. A., Nara, J. M., Piazza, R. M. F., et al. (2007). Aggregative adherence of uropathogenic Proteus mirabilis to cultured epithelial cells. FEMS Immunol. Med. Microbiol. 51, 319-326. doi: 10.1111/j.1574-695X.2007. 00308.x

Schembri, M. A., Christiansen, G., and Klemm, P. (2001). FimH-mediated autoaggregation of Escherichia coli. Mol. Microbiol. 41, 1419-1430. doi: 10.1046/j.1365-2958.2001.02613.x

Schluter, J., Nadell, C. D., Bassler, B. L., and Foster, K. R. (2015). Adhesion as a weapon in microbial competition. ISME J. 9, 139-149. doi: 10.1038/ismej.2014.174

Sherlock, O., Vejborg, R. M., and Klemm, P. (2005). The TibA adhesin/invasin from enterotoxigenic Escherichia coli is self recognizing and induces bacterial aggregation and biofilm formation. Infect. Immun. 73, 1954-1963. doi: 10.1128/IAI.73.4.1954-1963.2005

Simmons, B. P., Gelfand, M. S., Haas, M., Metts, L., and Ferguson, J. (1989). Enterobacter sakazakii infections in neonates associated with intrinsic contamination of a powdered infant formula. Infect. Control Hosp. Epidemiol. 10, 398-401. doi: 10.2307/30144207

Sjoblad, R. D., Doetsch, R. N., and Emala, C. W. (1985). Novel function of eubacterial flagella: role in aggregation of a marine bacterium. Arch. Microbiol. 142, 101-102. doi: 10.1007/BF00409246

Sourjik, V., and Wingreen, N. S. (2012). Responding to chemical gradients: bacterial chemotaxis. Curr. Opin. Cell Biol. 24, 262-268. doi: 10.1016/j.ceb.2011.11.008

Symington, A., Ballantyne, M., Pinelli, J., and Stevens, B. (1995). Indwelling versus intermittent feeding tubes in premature neonates. J. Obstet. Gynecol. Neonatal Nurs. 24, 321-326. doi: 10.1111/j.1552-6909.1995.tb 02483.x

Vadyvaloo, V., Viall, A. K., Jarrett, C. O., Hinz, A. K., Sturdevant, D. E., and Joseph Hinnebusch, B. (2015). Role of the PhoP-PhoQ gene regulatory system in adaptation of Yersinia pestis to environmental stress in the flea digestive tract. Microbiol. Read. Engl. 161, 1198-1210. doi: 10.1099/mic.0. 000082

van Acker, J., de Smet, F., Muyldermans, G., Bougatef, A., Naessens, A., and Lauwers, S. (2001). Outbreak of necrotizing enterocolitis associated with Enterobacter sakazakii in powdered milk formula. J. Clin. Microbiol. 39, 293-297. doi: 10.1128/JCM.39.1.293297.2001

Wang, L., Hu, X., Tao, G., and Wang, X. (2012). Outer membrane defect and stronger biofilm formation caused by inactivation of a gene encoding for heptosyltransferase I in Cronobacter sakazakii ATCC BAA894. J. Appl. Microbiol. 112, 985-997. doi: 10.1111/j.1365-2672.2012. 05263.x 
Wang, L., Qin, W., Yang, S., Zhai, R., Zhou, L., Sun, C., et al. (2015). The Adh adhesin domain is required for trimeric autotransporter Apa1mediated Actinobacillus pleuropneumoniae adhesion, autoaggregation, biofilm formation and pathogenicity. Vet. Microbiol. 177, 175-183. doi: 10.1016/j.vetmic.2015.02.026

Yang, J., and Zhang, Y. (2015). I-TASSER server: new development for protein structure and function predictions. Nucleic Acids Res. 43, W174-W181. doi: $10.1093 / \mathrm{nar} / \mathrm{gkv} 342$

Zhao, X., Norris, S. J., and Liu, J. (2014). Molecular architecture of the bacterial flagellar motor in cells. Biochemistry (Mosc.) 53, 4323-4333. doi: $10.1021 /$ bi500059y
Conflict of Interest Statement: The authors declare that the research was conducted in the absence of any commercial or financial relationships that could be construed as a potential conflict of interest.

Copyright (c) 2017 Hoeflinger and Miller. This is an open-access article distributed under the terms of the Creative Commons Attribution License (CC BY). The use, distribution or reproduction in other forums is permitted, provided the original author(s) or licensor are credited and that the original publication in this journal is cited, in accordance with accepted academic practice. No use, distribution or reproduction is permitted which does not comply with these terms. 